\author{
ORNL-2863 \\ UC -4 Chemistry-General
}

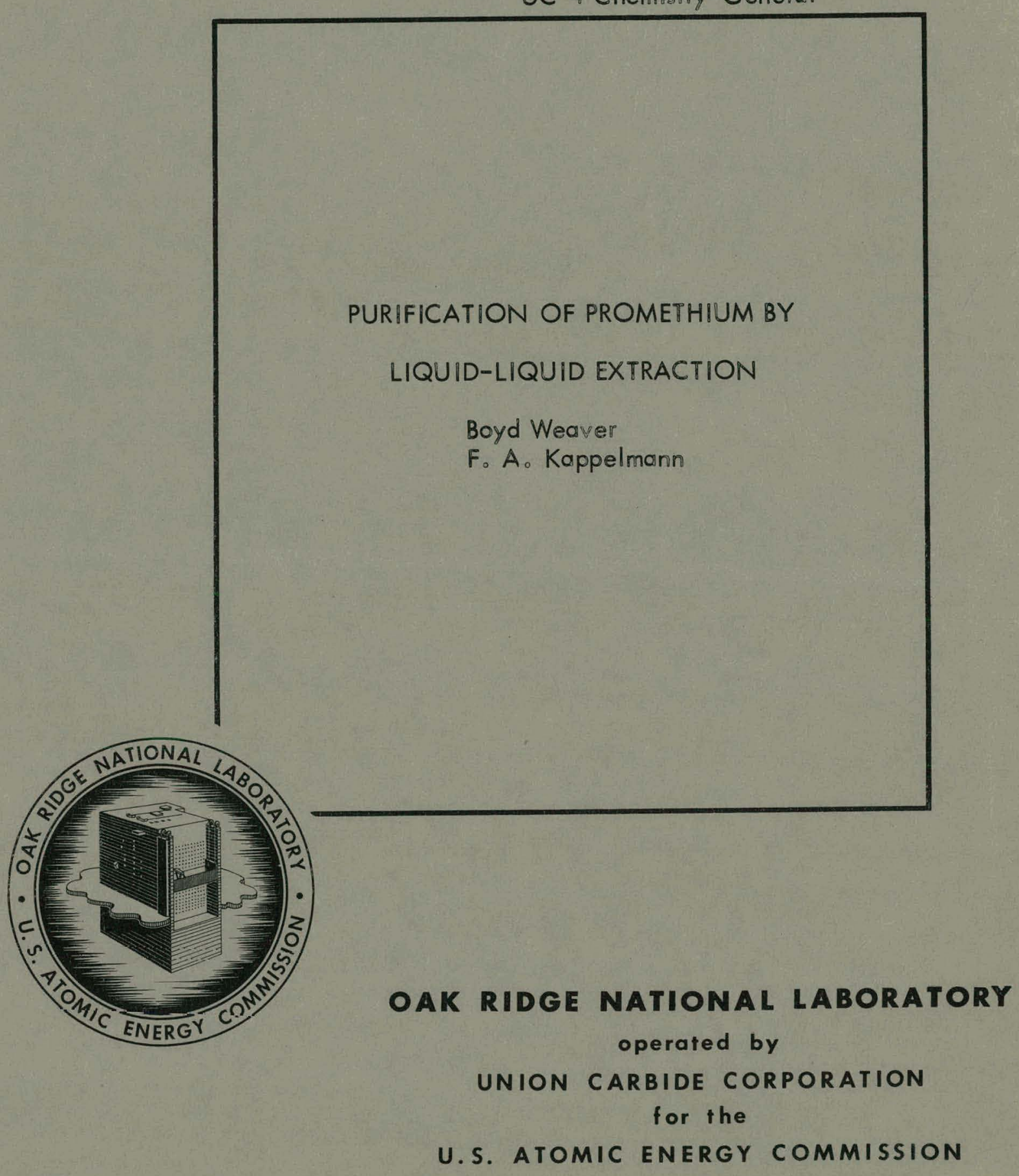

Boyd Weaver

F. A. Kappelmann

U.S. ATOMIC ENERGY COMMISSION 


\section{DISCLAIMER}

This report was prepared as an account of work sponsored by an agency of the United States Government. Neither the United States Government nor any agency Thereof, nor any of their employees, makes any warranty, express or implied, or assumes any legal liability or responsibility for the accuracy, completeness, or usefulness of any information, apparatus, product, or process disclosed, or represents that its use would not infringe privately owned rights. Reference herein to any specific commercial product, process, or service by trade name, trademark, manufacturer, or otherwise does not necessarily constitute or imply its endorsement, recommendation, or favoring by the United States Government or any agency thereof. The views and opinions of authors expressed herein do not necessarily state or reflect those of the United States Government or any agency thereof. 


\section{DISCLAIMER}

Portions of this document may be illegible in electronic image products. Images are produced from the best available original document. 
Printed in USA. Price 75 cents. Available from the

Office of Technical Services

Department of Commerce

Washington 25, D.C.

\section{LEGAL NOTICE}

This report wos prepared as an account of Government sponsored work. Neither the United States, nor the Commission, nor any person acting on behalf of the Commission:

A. Makes any warranty or representation, expressed or implied, with respect to the accuracy, completeness, or usefulness of the information contained in this report, or that the use of any information, apparatus, method, or process disclosed in this report may not infringe privately owned rights; or

B. Assumes any liabilities with respect to the use of, or for damages resulting from the use of any information, apparatus, method, or process disclosed in this report.

As used in the above, "person acting on behalf of the Commission" includes any employee or contractor of the Commission, or employee of such contractor, to the extent that such employee or contractor of the Commission, or employee of such contractor prepares, disseminates, or provides access to, any information pursuant to his employment or contract with the Commission, or his employment with such contractor. 


\author{
Contract No. W-7405-eng-26
}

CHEM ICAL TECHNOLOGY :DIVIS ION

Chemical Development Section C

\title{
PURIFICATION OF PROMETHIUM BY
}

LIQUU ID-L IQU ID EX'L'RACTION

Boyd Weaver and F. A. Kappelmann

DATE ISSUED

FEB 121960

\author{
OAK RIDGE NATIONAL LABORATORY \\ Oak Ridge, Tennessee \\ Operated by \\ UN ION CARBIDE CORPORATION \\ for the \\ U. S. ATOM IC ENERGY COMMISSION
}




\section{ABSTRACT}

A process was developed for separating promethium from mixed fission product rare earths by continuous multistage. countercurrent extraction with $100 \%$ tri-n-butylphosphate from nitric acid of 12 or higher concentration. Distribution coefficients at 12 N acidity for neodymium, promethium, and samarium are. $0.43,0.82$, and 1.5 .5$, respectively. Singlestage separation factors of 1.9 between successive elements can be maintained throughout the system to give separations dependent only on the number of stages. Extracted values can be recovered from the organic solution by stripping with a smaller volume of dilute nitric acid.

A flowsheet for purification of promethium includes one cycle for separation of promethium from neodymium and lighter elements and a second cycle for removal of samarium and heavier elements. Each cycle consists of a series of countercurrent partitioning stages, followed by stripping stages and an evaporator. With 20 stages in the first cycle and 34 stages. in the second, a $90 \%$ yield of promethium with a purity of $83 \%$ can be obtained from a typical mixture of fission product rare earths, assuming essentially perfect mechanical efficiency. An increase to 34 stages in the first cycle would permit a. $93 \%$ yield of $99 \%$ promethium. 
1.0 Introduction

Page

2.0 Flowsheet

3. 0 Experimental

3.1 Apparatus and Techniques

3.2. Single-stage Data

3.3 Eleven-stage Experiments and Data .. 10

3. 4 Twenty-stage Experiments and Data. 10

3.5 Thirty-four-stage Experiment and Data

3.6: Stripping

4. 0 Discussion 


\subsection{INTRODUCTION}

This report describes the development of a process for separating the synthetic element promethium from the other fission product rare earths. The process is to be applied on a production scale by the Isotopes. Division of the Oak Ridge National Laboratory. The order and nature of experiments performed were affected considerably by changes in aims and needs indicated by those interested in application. Chronologically these aims were: removal of yttrium in order to obtain less radioactive feed material for ion exchange columns; removal of lanthanum, praseodymium and most of the neodymium in order to decrease the bulk and increase the promethium capacity of ion exchange columns; and; finally, production of promethium of required purity by a two-cycle extraction process alone. The process adopted for cerium recovery also removed most of the yttrium, and the feasibility of promethium purification by extraction became more obvious as this study progressed. The feasibility of purifying promethium on a large scale depends on the maintenance of theoretical separation factors throughout a long series of stages, the absence of a buildup of rare earths sufficient to noticeably decrease distribution coefficients in any part of the system, and the quantitative stripping of the extracted elements from the organic stream into a reasonable volume of dilute nitric acid.

The nature of the equipment used for multistage experiments and its location were: such that processing of radioactive materials was not feasible. Therefore no promethium was present in any of these experiments. However, singlestage experiments established the relation between promethium and the neighboring elements well enough that accurate information for promethium can be obtained by interpolation in data obtained from mixtures of neodymium and samarium. The accuracy of multistage data was limited by the accuracy of spectrographic analysis.

This phase of the development-was carried only to the point that feasibility of a suggested flowsheet appeared to have been established and assemblies of stainless steel Knowles-type mixer settlers became available in the Isotopes Division. At this point development was transferred there. Preliminary tests with individual tracer elements have confirmed predictions made from the results of experiments reported here.

Peppard et al. ${ }^{l}$ first reported the separation of rare earths by extraction with tributyl phosphate from concentrated nitric and hydrochloric acids. Distribution coefficients, i.e., ratios of concentration in the organic phase to concentration in the aqueous phase, increased with acidity. 
Separation factors, j.e., ratios of distribution coefficients, between successive rare-earth elements in the fission product range were about 1.9 with acidities above $10 \mathrm{~N} \mathrm{HNO}_{3}$. Much information concerning these extractions and separations has been contributed by McKay et al. ${ }^{2}$ Spedding et al. ${ }^{3}$ studied the separation of rare earths in concentrated solutions of low acidity. In this laboratory natural rare earths have been separated on a kilogram scale by Weaver et al. 4 Brezhneva ${ }^{5}$ et al. report a multistage distributive separation of fission product rare earths.

The authors gratefully acknowledge the very careful second-shift operation of the separation cascade by $J$ 。 $P$. Eubanks. R. E. McHenry was helpful in keeping the course of the investigation related to the prospective needs of the Isotopes Division. Spectrographic analyses were devised and performed by $J$. A. Norris and associates in the Analytical Chemistry Division. Tracer distribution data were obtained by Janet Debnam and $J$ 。 P. Eubanks.

\subsection{FLOWSHEET}

A two-cycle flowsheet was devised on the basis of data obtained in a laboratory-scale study (Fig。1). Indicated flow rates for the first cycle are a 10 -fold scaleup of those suitable for the experimental equipment. The second cycle fits the experimental equipment and is adequate to handle the product of the first cycle. There are no chemical limitations on scaleup to a production plant.

One conspicuous lack in the above flowsheet is the number of stages in each separations cascade. The production plant of the Isotopes Diviston has 20 stages in the first cascade and 34 stages in the second. The first cascade is limited to a separation factor of $\sim 500$ between promethium and neodymium, while the 34 stages of the second cascade allow a factor of $\sim 35,000$ between samarium and promethium. The yield and/or purity of the promethium is severely limited by the small number of stages in the first cascade. The first section of Table 1 shows one calculated possible result of operation of this cascade. The yield of promethium was arbitrarily set at $90 \%$ in the first cycle and the samarium removal at $99 \%$ in the second. Attainable separations are calculated from a single stage separation factor of 1.85 between successive elements. Quantities are based on feed containing $1000 \mathrm{~g}$ of mixed fission product rare earths. The composition of the feed material is calculated from the expected results of removing cerium from a mixture of arbitrary but possible composition. An increase to 25 stages in the first cascade allows an increase in promethium purity to $93 \%$ (Table 1, middle section). There is more need for high separation power in the first cycle than in the second 
Feed - $25 \mathrm{~g} \mathrm{RE} /$ liter $12.5 \mathrm{~N} \mathrm{HNO}_{3}$

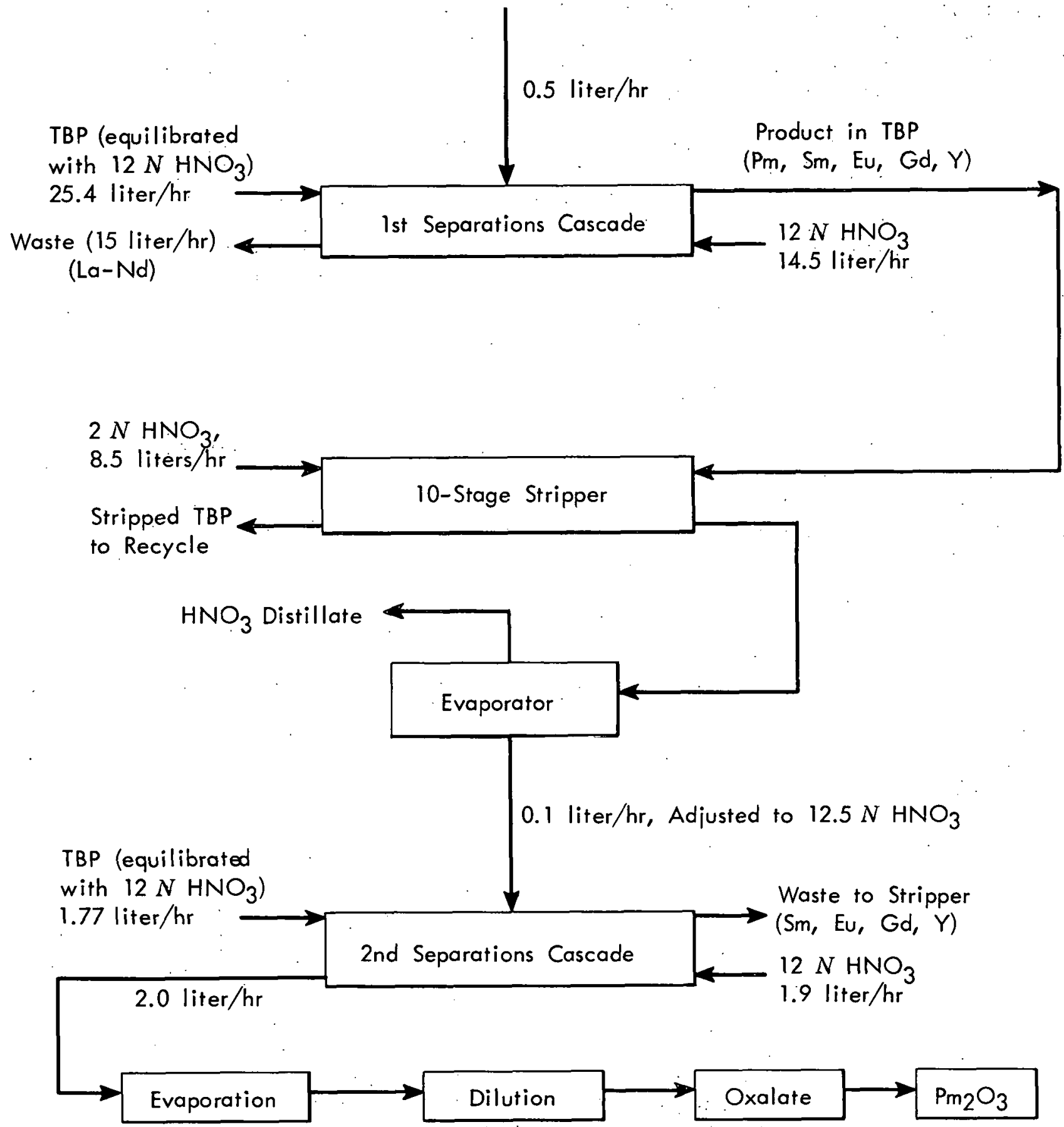

Fig. 1. Promethium purification flowsheet. 
Table. 1. Calculated Material Balance

in Promethium Purification

34 stages in 2 nd cycle

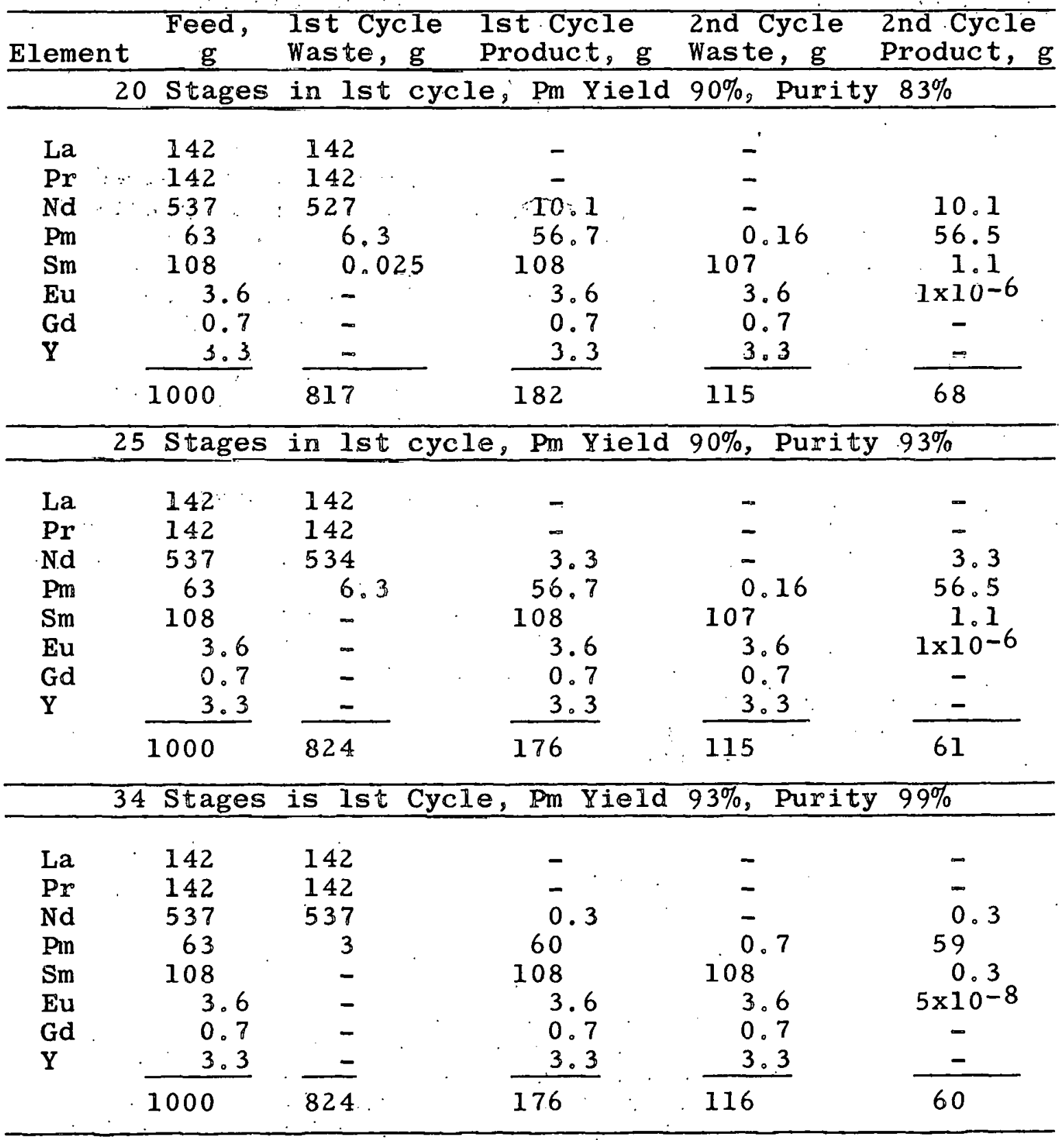

because neodymium is the major constituent of the original mixture. With 34 stages in each cascade it would be possible to obtain a $93 \%$ yield of $99 \%$ promethium (Table 1 , bottom section). 
While this flowsheet is based on 12 N $\mathrm{HNO}_{3}$, operation at higher acidity is feasible. Relative flow rates would be different. with a smaller organic flow, but separation factors would be only very slightly higher. Suitable flow rates for any acidity for which distribution coefficients are known can be calculated without further experiments.

\subsection{EXPER IMENTAL}

\subsection{Apparatus and Tẹchniques}

Single-stage data were obtained by contacting prepared phases in separatory funnels, separating the phases, pipetting 2-ml samples of each phase into a culture tube with a cork stopper, and measuring the gamma activity in a welltype scintillation counter. Tracers used were $\mathrm{Nd}^{147}$, $\mathrm{Pm} 148$, and $\mathrm{Sm} 153$ obtained from Isotopes Division stocks. Nitric acid concentrations were determined by titrating the 2-ml samples in water with standard 1 N NaOH to a methyl orange end point. Distribution coefficients were ratios of counts per unit time in the two phases.

The basic unit of the multistage extraction system was a glass mixer-settler (Fig. 2). The desired number of these units were connected in series by: Tygon tubing containing an adjustable gravity leg for control of the interface height in each stage. The central pumping impeller and mixing blades were powered by a $0.01 \mathrm{hp}$ Bodine motor attached to each shaft by tubing. Since the impeller in this mixer-settler pumps whatever liquid becomes available to it, there was no internal control of the flow rates. The most frequent cause of interruption was the breakage of glass shafts. The process streams were supplied by Milton Roy proportioning pumps and microbellows pumps. The chief activity of the operator was the checking of flow rates by measuring feed or effluent volumes. Evaporators were continuous and were constructed of glass pipe with steam-heated tantalum fingers. There was sufficient difficulty in maintaining constant flow rates into the system and uninterrupted flow through all the mixer-settlers that attainment of equilibrium was far from routine. In several experiments the full efficiency of the chemical system. was not obtained from the mechanical system. Moreover, lack of equilibrium was not always obvious and became evident only on later analysis. With the low concentrations used in most of these experiments, adequate sampling required termination of experiments and the use of large fractions of the total volumes as samples. In each experiment at least $25 \mathrm{hr}$ of steady operation were allowed for attainment of equilibrium.

3. 2 Single-stage Data

Extraction of both neodymium and promethium increased with acidity up to about $4 \stackrel{\mathrm{N}}{\mathrm{HNO}_{3}}$ and then decreased slowly 


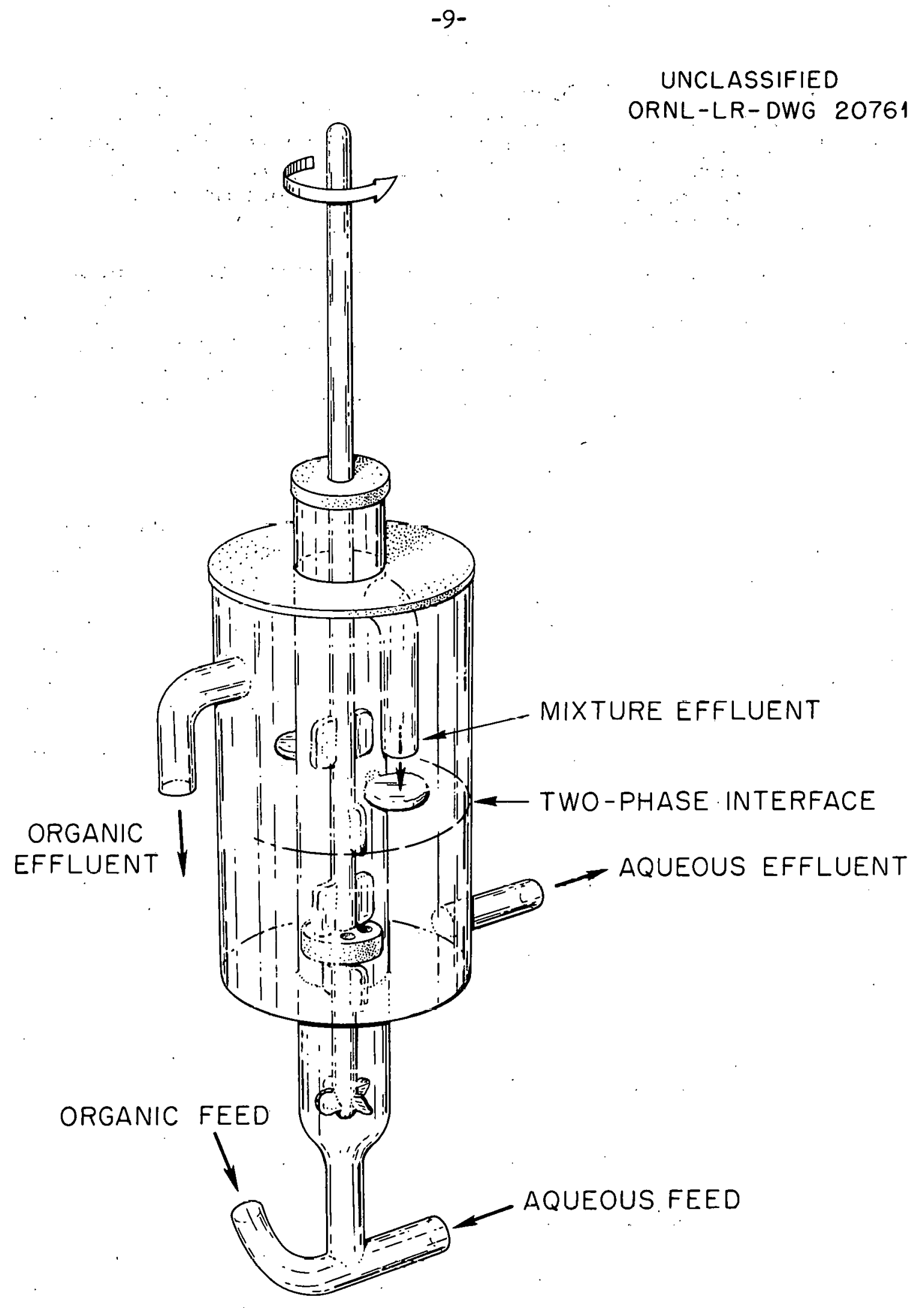

Fig. 2. Pump mixer-settler. 
to nearly $8 \underline{\mathrm{N}} \mathrm{HNO}_{3}$, before increasing rapidly with higher acidity (Fig. 3). The extraction coefficient of samarium from about $12 \underline{N}$ acid has been measured repeatedly. Readings from these curves give coefficients of $0.43,0.82$, and 1.55 , respectively, for neodymium, promethium, and samarium. The calculated separation factor for both pairs is 1.9 .

In the middle acid range, coefficients are low enough to permit stripping of the rare earths from the TBP by a volume of acid equal to or somewhat less than the volume of TBP. Since nitric acid distributes between. TBP and water, its countercurrent stripping maintains the acidity in a suitable range for stripping the rare earths if the proper flow ratios are used.

\subsection{Eleven-stage Experiments}

In the first experiment, designed (Table 2 , part a) to determine the separability of yttrium from neodymium, $99 \%$ of the yttrium. was concentrated in the extract, which contained only $7 \%$ of the total feed. . The apparent absence of neodymium in the extract prevented the calculation of separation factors between neodymium and other elements. Analys is of both phases in 6 of the 11 stages (Fig. 4) showed that the highest concentration in any stage was less than $2 \mathrm{~g}$ of $\mathrm{RE}_{2} \mathrm{O}_{3}$ per 1iter. This is less than $1 \%$ of the loading capacity of TBP. The highest concentration was at the feed point.

In a second experiment the organic/aqueous flow ratio was increased in order to measure the separation between samarium and neodymium (Table 2 , part b)。 The indicated overall separation factor between samarium and neodymium is 880 , or 3.42 per. stage. The corresponding calculated $\mathrm{Sm} / \mathrm{Pm}$ and $\mathrm{Pm} / \mathrm{Nd}$ factors are 1.85.. This is very near the experimental single-stage value of 1.9 , indicating a high efficiency in the separation system.

When the feed point was at stage 9 , the maximum concentration of total rare earths remained at this point (Fig. 5), but the concentration of neodymium was at a maximum nearer the middle of the cascade (Fig. 6). The neodymium concentration decreased rapidly above the feed point.

\section{3:4 Twenty-stage Experiments and Data}

When it became certain that the Isotopes Division would have equipment with 20 stages for separation of promethium from neodymium, experiments were performed with 20 glass mixer-settlers. Flow rates were chosen (Table 3 ) so as to split between promethium and neodymium, on the basis that their distribution coefficients from $12 \cdot \mathrm{N} \mathrm{HNO}_{3}$ were 0.95 and 0.46 , respectively. : Though there is considerable uncertainty 


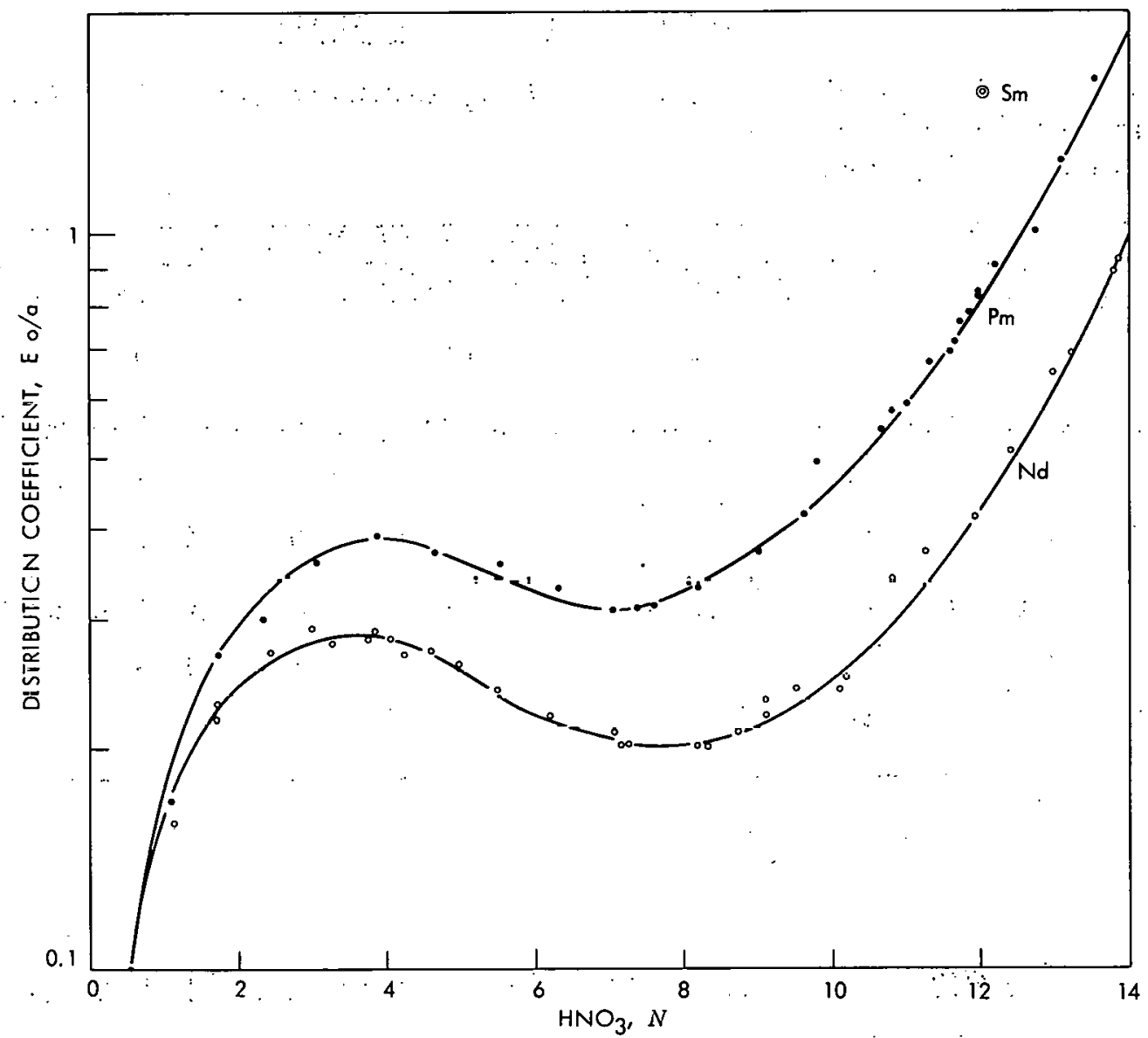

Fig. 3 Extraction of neodymium, promethium, and samarium by pure TBP from $\mathrm{HNO}_{3}$.

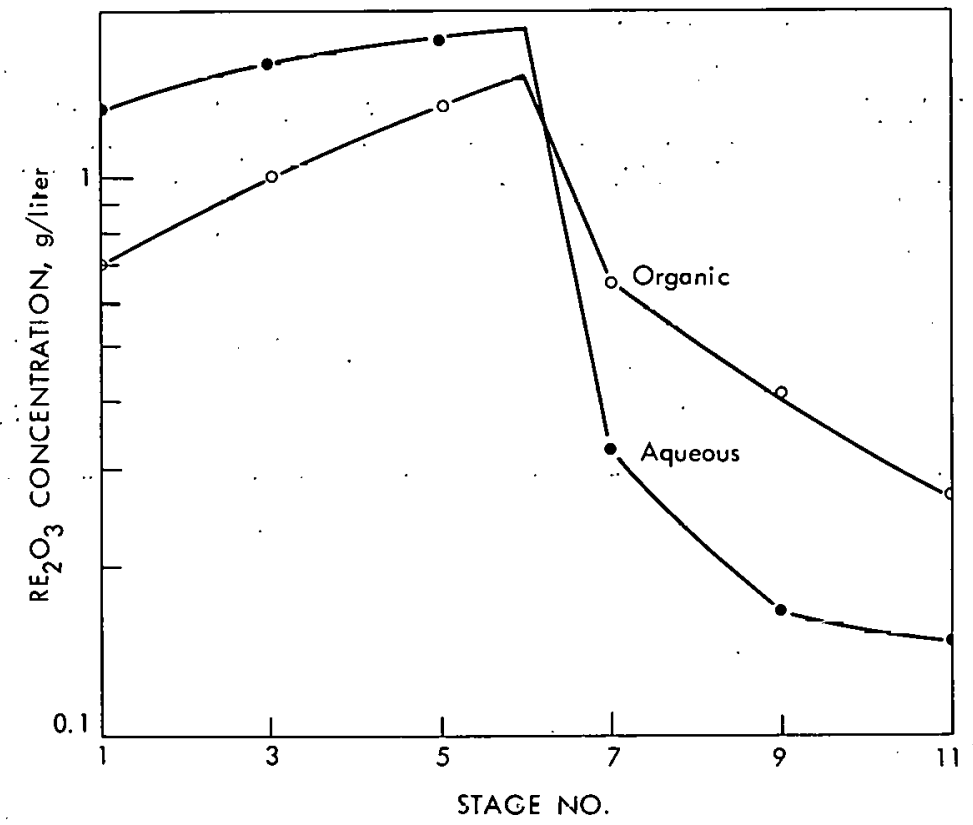

Fig. 4. Rare earth concentration profiles in.11-stage cascade feed in stage 6 . 
Table 2. Eleven-stage Separation of Neodymium from

(a) Yttrium and (b) Samarium

Feed: $\quad 250 \mathrm{ml} / \mathrm{hr}$ of $12.5 \mathrm{~N} \mathrm{HNO}_{3}$ containing $2.5 \mathrm{~g} \mathrm{RE}_{2} \mathrm{O}_{3}$ Organic: $100 \%$ TBP

Aqueous: $12 \cdot \mathrm{N} \cdot \mathrm{HNO}_{3}$

\begin{tabular}{|c|c|c|c|c|c|c|c|c|c|}
\hline Stream & $\begin{array}{c}\mathrm{RE}_{2} \mathrm{O}_{3} \\
\mathrm{~g} / \mathrm{hr} \\
\end{array}$ & $\mathrm{La}_{2} \mathrm{O}_{3}$ & $\begin{array}{r}\mathrm{An} \\
\mathrm{Pr}_{6} \mathrm{O}_{11} \\
\end{array}$ & $\frac{a 1 y s \text { is }}{\mathrm{Nd}_{2} \mathrm{O}_{3}}$ & $\begin{array}{l}\% \text { of } \\
\mathrm{Sm}_{2} \mathrm{O}_{3} \\
\end{array}$ & $\begin{array}{l}\text { Total } \\
\mathrm{Eu}_{2} \mathrm{O}_{3} \\
\end{array}$ & $\begin{array}{l}\mathrm{RE}_{2} \mathrm{O}_{3} \\
\mathrm{Gd}_{2} \mathrm{O}_{3} \\
\end{array}$ & $\mathrm{Dy}_{2} \mathrm{O}_{3}$ & $\overline{\mathrm{Y}_{2} \mathrm{O}_{3}}$ \\
\hline Feed & 2.5 & 15 & 3.3 & 61 & 14 & 0.15 & 0.4 & - & 5.5 \\
\hline (a) Feed & into $\mathrm{St}$ & age 6 ; & organi & c 600 & $\mathrm{~m} 1 / \mathrm{hr}$ & aqueor & us 1500 & $0 . \mathrm{ml} / \mathrm{hr}$ & \\
\hline Organic & 0.178 & - & - & - & 8.8 & 0.3 & 5.2 & 0.3 & 86 \\
\hline Raffinate & 2.24 & 15 & 4.4 & 67 & $12: 8$ & 0.05 & 0.1 & - & ₹0.1 \\
\hline (b) Feed & into $\mathrm{st}$ & age 8 ; & organi & c 1100 & $\mathrm{~m} 1 / \mathrm{hr}$ & , aquec & ous 950 & $\mathrm{ml} / \mathrm{hr}$ & \\
\hline Organic & 0.5 & - & - & 8.7 & 59 & 0.14 & 1.8 & - & 30 \\
\hline Raffinate & 2.0 & 20 & 5 & 74. & 0.57 & - & - & - & - \\
\hline
\end{tabular}

Table 3. Twenty-stage Separation of Samarium from Neodymium

Feed: $\quad 250 \mathrm{ml} / \mathrm{hr}$ of $12.5 \mathrm{~N} \mathrm{HNO}_{3}$ containing $2.5 \mathrm{~g} \mathrm{RE}_{2} \mathrm{O}_{3}$ Organic: $1000 \mathrm{ml} / \mathrm{hr}$ TBP pre-equilibrated with $3 \underline{\mathrm{N}} \mathrm{HNO}_{3}$ Aqueous: $850 \mathrm{ml} / \mathrm{hr} 12 \cdot \mathrm{N} \mathrm{HNO}_{3}$

\begin{tabular}{lcccccc}
\hline Stream & $\begin{array}{r}\mathrm{RE}_{2} \mathrm{O}_{3} \\
\mathrm{~g} / \mathrm{hr}\end{array}$ & \multicolumn{5}{c}{ Analysis, $\%$ of Total $\mathrm{RE}_{2} \mathrm{O}_{3}$} \\
\hline Feed & 2.5 & 17 & 4 & 60 & 15 & 5.5 \\
Organic & 0.48 & - & - & 2 & 71 & 27 \\
Aqueous & 2.02 & 20 & 3 & 77 & 0.02 & - \\
\hline
\end{tabular}


UNCLASSIFIED

ORNL-LR-DWG 42840

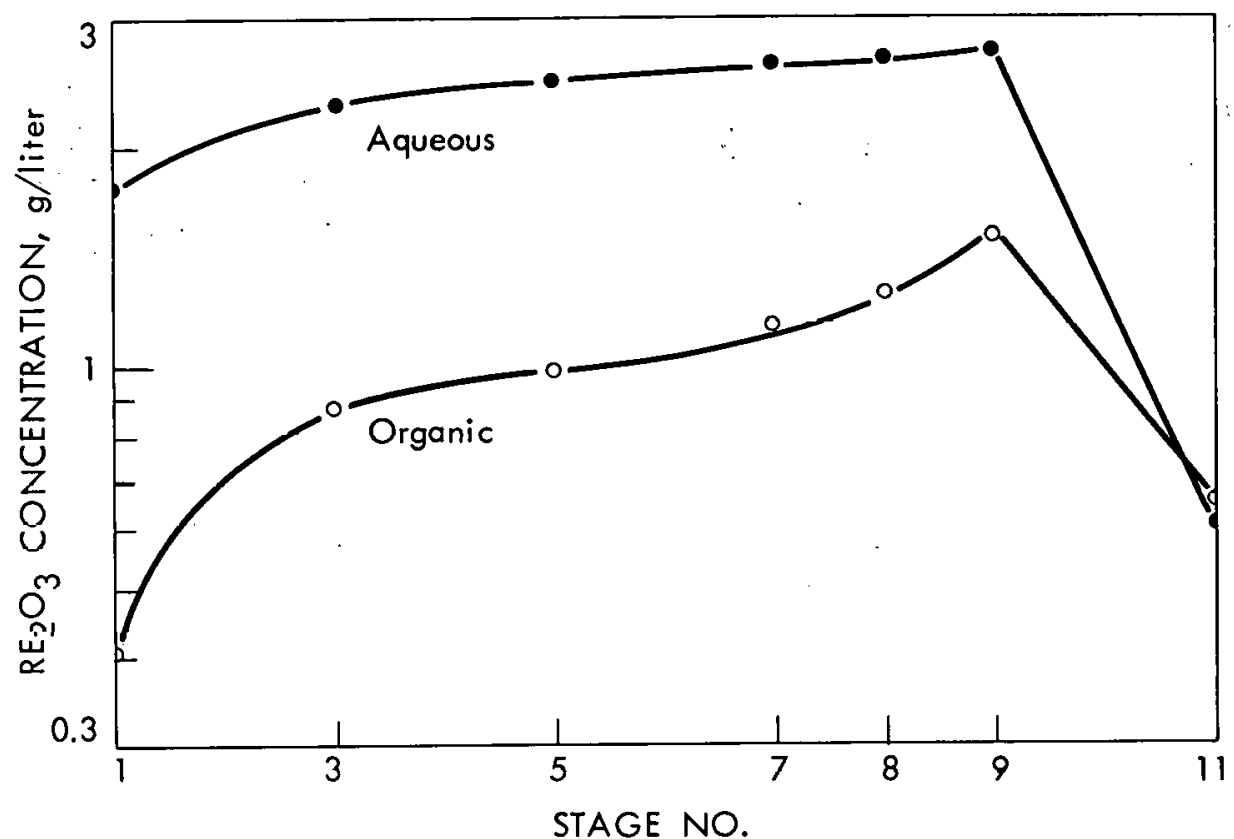

Fig. 5. Rare earth concentration profiles in 11-stage cascade, feed in stage 9.

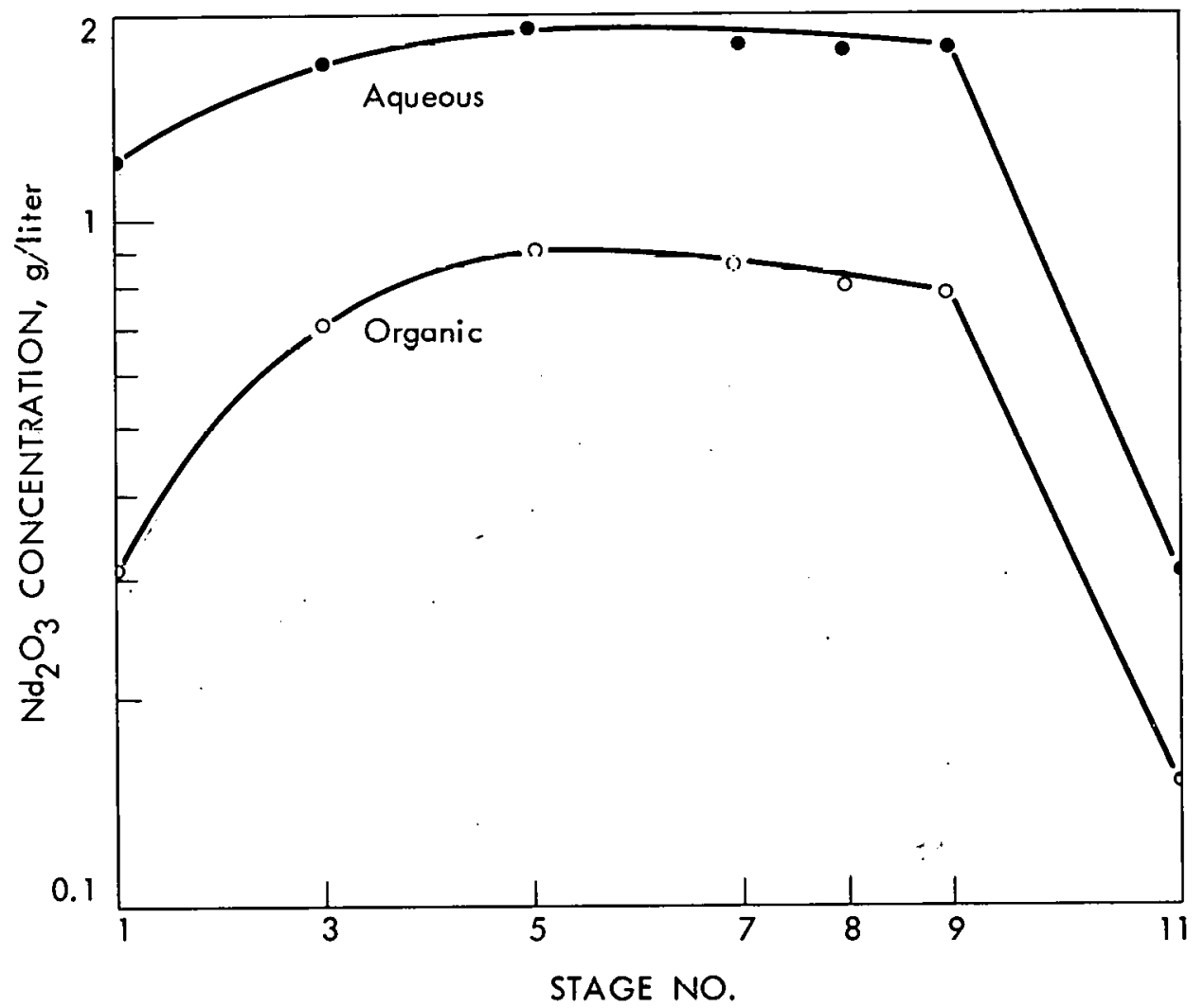

Fig. 6. Neodymium concentration profiles in 11-stage cascade, feed in stage 9. 
in the small value of $0.02 \% \mathrm{Sm}_{2} \mathrm{O}_{3}$ in the raffinate, the indicated overall $\mathrm{Sm} / \mathrm{Nd}$ separation factor is 200,000 , or nearly 3 . 2 per stage. This approaches the experimental single-stage value. Analysis of both phases of 13 of the 20 stages (Fig. 7 ) showed that the highest concentration in the solvent was only $0.8 \mathrm{~g}$ of $\mathrm{RE}_{2} \mathrm{O}_{3}$ per liter.

Experiments were performed to obtain data to be used as a guide in determining the proper feed points for specific yields and purities. In most of these experiments imperfect performance of one or more of the mixer-settlers prevented attainment of equilibrium and full efficiency of the system and decreased usefulness of the data. However, this information can be calculated as accurately as it can be determined with perfectly efficient apparatus.

\subsection{Thirty-four-stage Experiment and Data}

The Isotopes Division has 34 stages available for the separation of samarium from promethium. Two experiments were performed in the glass apparatus with 34 stages, though the separation expected was too high for measurement. A small difference in the organic flow rate (Table 4) made a marked difference in the amount of samarium extracted. In neither case was enough neodymium extracted to make possible a calculation of a separation factor.

\subsection{Stripping}

Stripping from the organic phase was studied. Extraction data indicate that stripping should be maximum with aqueous acidities between 5 and $8 \mathrm{~N}$ and that in 10 stages stripping should be essentially complete with organic/aqueous flow ratios up to 4 . The acidity of the stripping solution will increase toward the stage from which it leaves the system, with the acid level depending somewhat on the acidity of the original strip solution but more on the flow ratio. When the organic effluent from a 20-stage separation experiment was stripped in 10 stages with $1 / 4$ volume of $4 \mathrm{~N} \mathrm{HNO}_{3}$, the final acidity of the strip solution was nearly $10^{-} \mathrm{N}$ (Fig. 8). Stripping with $2 \mathrm{~N} \mathrm{HNO}_{3}$ gave a slightly less acid effluent. It appears advisable to maintain an aqueous/organic ratio of at least $1 / 3$, though the spectrographic laboratory reported that no rare earths were detectable in the TBP from the stripping experiment.

\subsection{DISCUSSION}

The separation of natural rare earths is limited by concentration effects. Rare earths are extracted by formation of complexes with TBP of the form $\mathrm{RE}\left(\mathrm{NO}_{3}\right)_{3} \cdot 3 \mathrm{TBP}$. Pure TBP is approximately equivalent to a $1 \mathrm{M}$ rare earth solution. Distribution coefficients are constant only at low concentrations 
UNCLASSIFIED

ORNL-LR-DWG 42844

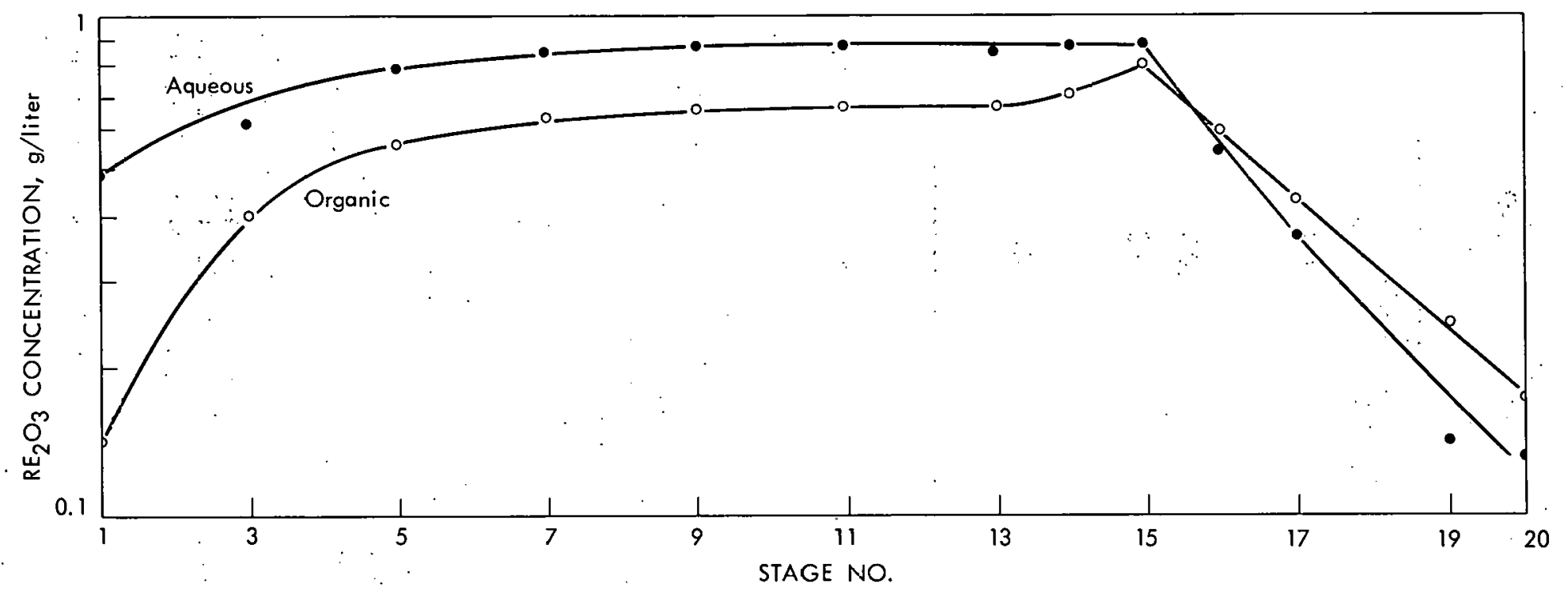

Fig. 7. Rare earth concentration profiles in 20-stage cascade.

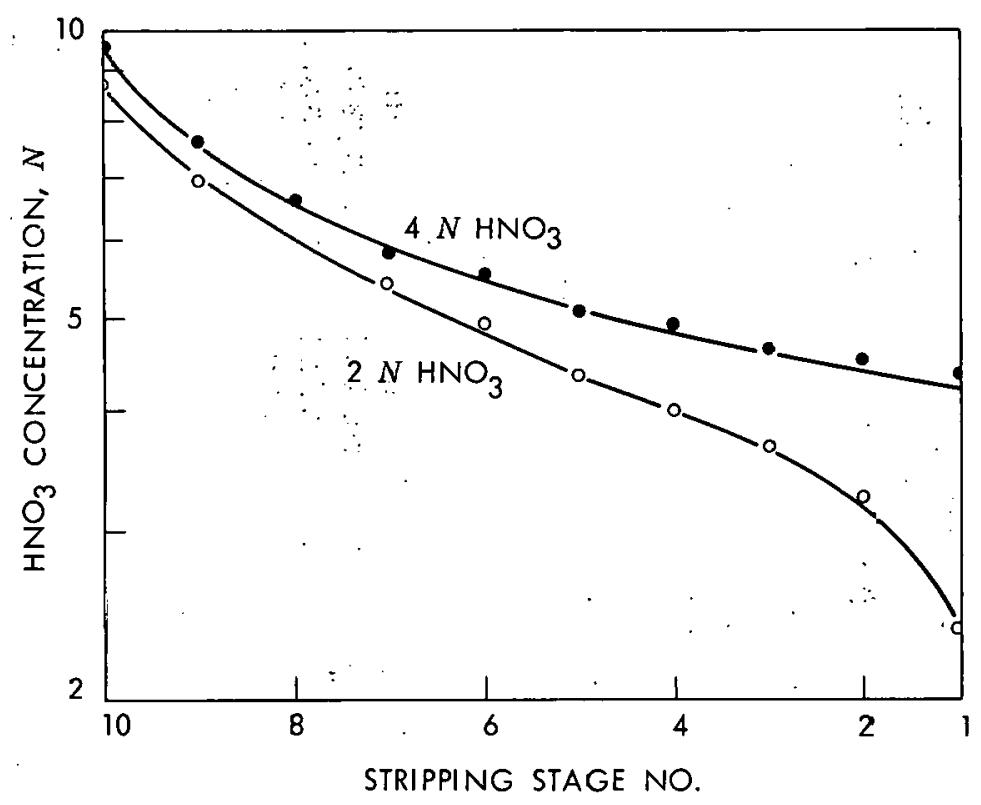

Fig. 8. Profile of stripping acicity. 
Table 4. Thirty-four-stage Separation

of Samarium from Neodymium

Feed: $\quad 100 \mathrm{mi} / \mathrm{hr} 12.5 \underline{\mathrm{N}} \mathrm{HNO}_{3}$ containing $4.0 \mathrm{~g} \mathrm{RE}_{2} \mathrm{O}_{3}$ Organic: $100 \%$ TBP pre-equilibrated with 12 N $\mathrm{HNO}_{3}$ Aqueous: $1900 \mathrm{ml} / \mathrm{hr} 12 \underline{\mathrm{N}} \mathrm{HNO}_{3}$

\begin{tabular}{lccc}
\hline Stream & $\begin{array}{c}\mathrm{RE}_{2} \mathrm{O}_{3}, \\
\mathrm{~g} / \mathrm{hr}\end{array}$ & $\begin{array}{c}\text { Analysis, \% of } \\
\text { Feed }\end{array} \mathrm{Td}_{2} \mathrm{~T}_{3}$ & $\mathrm{Sm}_{2} \mathrm{O}_{3}$ \\
\hline (a) Organic & $1520 \mathrm{ml} / \mathrm{hr}$ & 6 & 94 \\
Organic & 2.28 & - & 100 \\
Aqueous & 1.64 & 22 & 78 \\
(b) Organic & $1770 \mathrm{ml} / \mathrm{hr}$ & & \\
Organic & 4.03 & - & 100 \\
Aqueous & 0.22 & 96 & 4 \\
\hline
\end{tabular}

and decrease as loading of the solvent increases (Fig.9) In extractions from as little as $0.1 \mathrm{M}$ rare earth nitrate, the effective free reagent concentration is decreased by $10 \%$. Wi th a third-power dependency of extraction coefficients on reagent concentration, there is considerable variation in coefficients throughout a multistage system, greatly decreasing its efficiency. This effect increases with atomic number and the consequently greater extractability. Therefore, the lighter and more abundant elements are more easily separated than are the heavier and rarer ones.

In the separation of fission product rare earths, the disadvantages of liquid extraction are greatly diminished. The value of the material is measured in curies of activity rather than in weight units. Highly active solutions can be obtained without excessive loading of the extractant. Only the lighter rare earths and yttrium are present. There is no great localization of activity as in the case of ion exchange, but effluent concentrations and flow rates may be higher.

Extracted values may be stripped from the TBP by dilute nitric acid, and all aqueous nitrate solutions may be concentrated to any desired degree by evaporation.

The purpose of this investigation was not to demonstrate the efficiency of any given contacting device but to determine whether the separation factors indicated by single-stage distribution data can be extended to a multistage system, and to obtain some information on the limitations on concentrations, and consequently on throughput capacity, and on necessary 
UNCLASSIFIED

ORNL-LR-DWG 16709

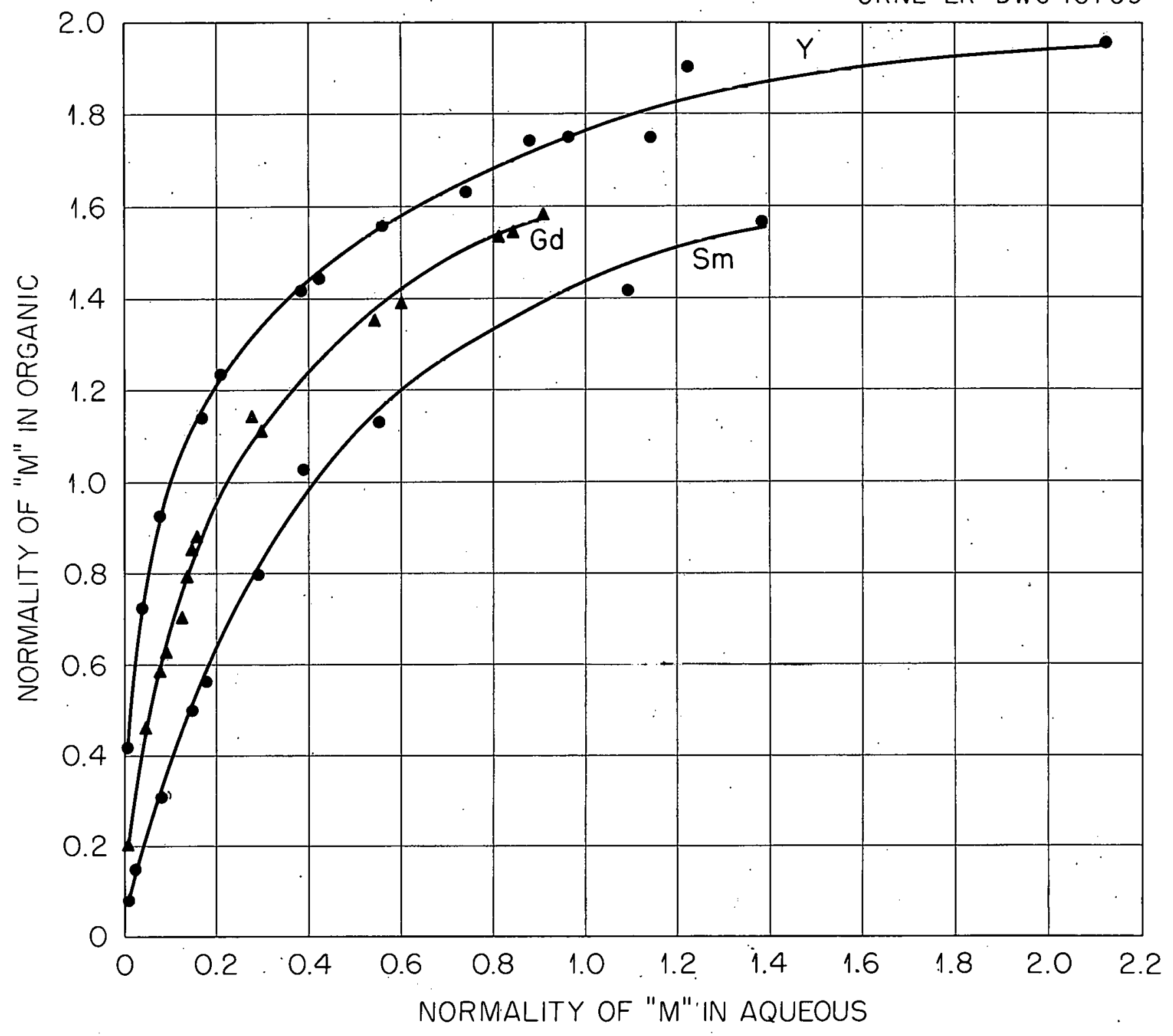

Fig. 9. Distribution of elements between TBP and $14.2 \mathrm{NHNO}_{3}$. 
ratios of stripping solutions to organic flow. The most likely hindrance to full efficiency in the separation cascade would be excessive buildup of concentration around the feed point from internal reflux. The attainment of theoretical separation in an experiment would indicate complete efficiency of all stages in the separation device and confirm the soundness of the predictions from single-stage data. These aims were realized or closely approached in several experiments. Though effective separations were accomplished with feed flows up to one-fifth of the total aqueous flow and with concentrations up to $2.5 \mathrm{~g} / 1$ iter, the slight buildup of concentration around the feed point indicates the advisability of limiting feed flows to $5 \%$ of the total aqueous flow and aqueous concentrations in the cascade to $1 \mathrm{~g} / 1$ iter. This is adequate for separation of large quantities of promethium in reasonably small equipment.

Distribution of elements and separation between them in a liquid-liquid extraction system are governed by simple arithmetical reiations. The distribution coefficient, EO, of a given element is the ratio of its concentration in the organic phase to that in the aqueous phase at equilibrium. The separation factor between two elements, $\alpha$, in a given system is the ratio of their distribution coefficients; i.e. , $\alpha_{1,2}=E_{1} / E_{2 \cdot:}$ In a single-stage distribution of an element, the ratio of quantities in the two phases is the product of the distribution coefficient and the ratio of organic and aqueous volumes; $i_{\circ} e_{\circ}, E_{a}^{O} \times V_{O} / V_{a}$. In a multistage countercurrent system with continuous feed at an intermediate stage and takeoff at both ends, an element tends to appear preferentially in the organic effluent when $E_{a}^{O} \cdot V_{o} / V_{a}$ is greater than unity, but in the aqueous effluent, or raffinate, when this product is less than unity. In a continuous system the $V$ 's represent flow rates rather than volumes. Separation between a pair of elements can be obtained by adjusting $V_{0} / V_{a}$ so that $\mathrm{E}_{\mathrm{O}}^{\mathrm{O}} \mathrm{V}_{\mathrm{O}} / \mathrm{V}_{\mathrm{a}}$ is greater than unity for one element and less than unity for the other. The elements will be distributed symmetrically in the cascade and their ratios in the effluents will be reciprocals if $V_{a} / V_{0}=\left(E_{1} / E_{2}\right)^{1 / 2}$ and the feed point is in the center stage.

In devising a flowsheet for this system, the aim has been to maintain this arithmetical relation regardless of the position of the feed point. The distribution of the two elements at equilibrium will tend to be symmetrical about the feed point, but the ratios of the two elements in each terminal stage will depend on the number of stages from the feed point to this stage. The introduction of a feed results in different flow ratios, or operating lines, in the two parts of the cascade. In the present case, compensation can be provided by increasing the acidity of the larger aqueous flow by introducing the feed at a higher acidity. This also results 
in slightly different equilibrium lines on either side of the feed point. This small effect is neglected in the calculations which follow.

In a continuously producing cascade with no external reflux, a total separative power of $n$ stages is $\alpha^{n / 2}$. With total reflux it would be $\alpha^{n}$, but there would be no production. This separative power may be distributed to the advantage of purity or yield of either element by shifting the feed point.

One method of determining the location of a feed point that will give a specified yield of one element with a specified limit on contamination by another is the use of McCabeThiele diagrams. It is necessary to have sufficient separative power in the cascade and to know the extraction coefficients of the two elements.

Figures 10 and 11 are McCabe-Thiele diagrams by which the proper feed point is determined for a $90 \%$ yield of promethium with decontamination from neodymium by a factor of 50. With a single-stage separation factor of 1.85 , this separation can barely be accomplished with 20 stages. Figure 10 is the diagram for the promethium yield. The slope of the promethium equilibrium line (E.L。) is 0.82 . Since the distribution coefficient of neodymium is 0.43 , the ideal operating line $\left(0 . \mathrm{L}_{\text {. }}\right)$ is $(0.82 \times 0.43)^{1 / 2}=0.59$. Assuming a feed flow of 0.05 times the total aqueous flow below the feed point, the slope of the operating 1 ine above the feed point is 0.56 . The ratio of promethium in the extract to that in the raffinate is $9 / 1$. The graphical solution shows that 8 stages or slightly more below the feed point are required for $90 \%$ promethium recovery.

Figure 11 is a graphical determination of the number of stages required to reduce the neodymium content by a factor of 50. The slope of the neodymium equilibrium line is 0.43 and the operating lines are the same as above. The graph shows that 11 stages are required above the feed point. The required feed point for a yield of $90 \%$ promethium with a $50 / 1$ decontamination from neodymium is in the ninth stage. There are barely 11 stages left out of a total of 20. This agrees with the fact that an overall separation factor of 450 is required and 20 stages give 1.910 or $\sim 600$.

When the required overall separation factor is very large, one or both of the diagrams will be difficult to read unless drawn on a large scale. Then a second method of determining the feed point may be more convenient. The point may be calculated as it has been done by Benedict and Pigford for hafnium-zirconium separations. For $95 \%$ yield of promethium, with decontamination from samarium by a factor of 200 , from a promethium-samarium mixture containing $34 \%$ promethium and $61.5 \%$ samarium, the solution is as follows: 
UNCLASSIFIED

ORNL-LR-DWG 42841

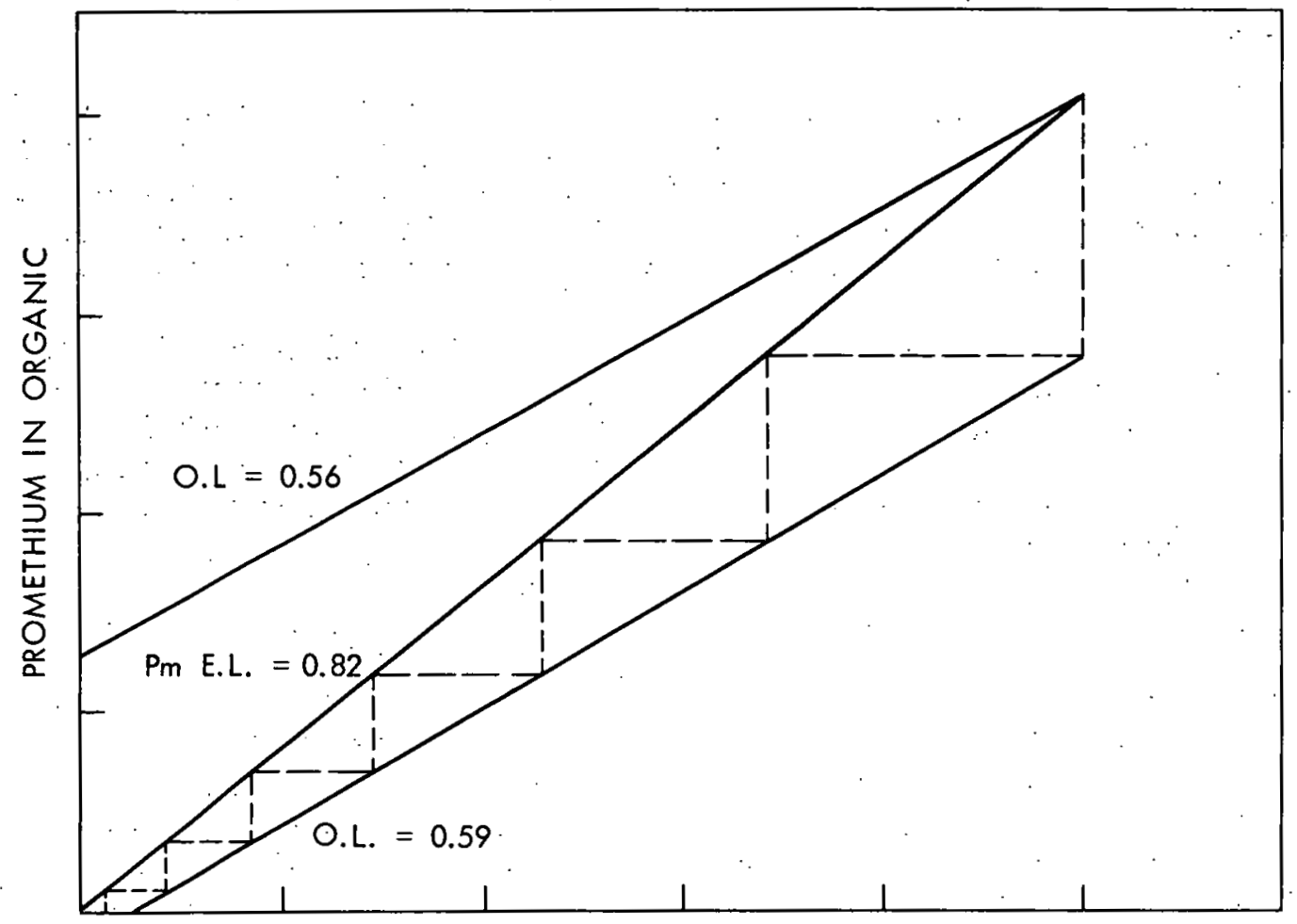

PROMETHIUM IN AQUEOUS

Fig. 10. Determination of feed point for $90 \%$ yield of promethium. Arbitrary concentration units.

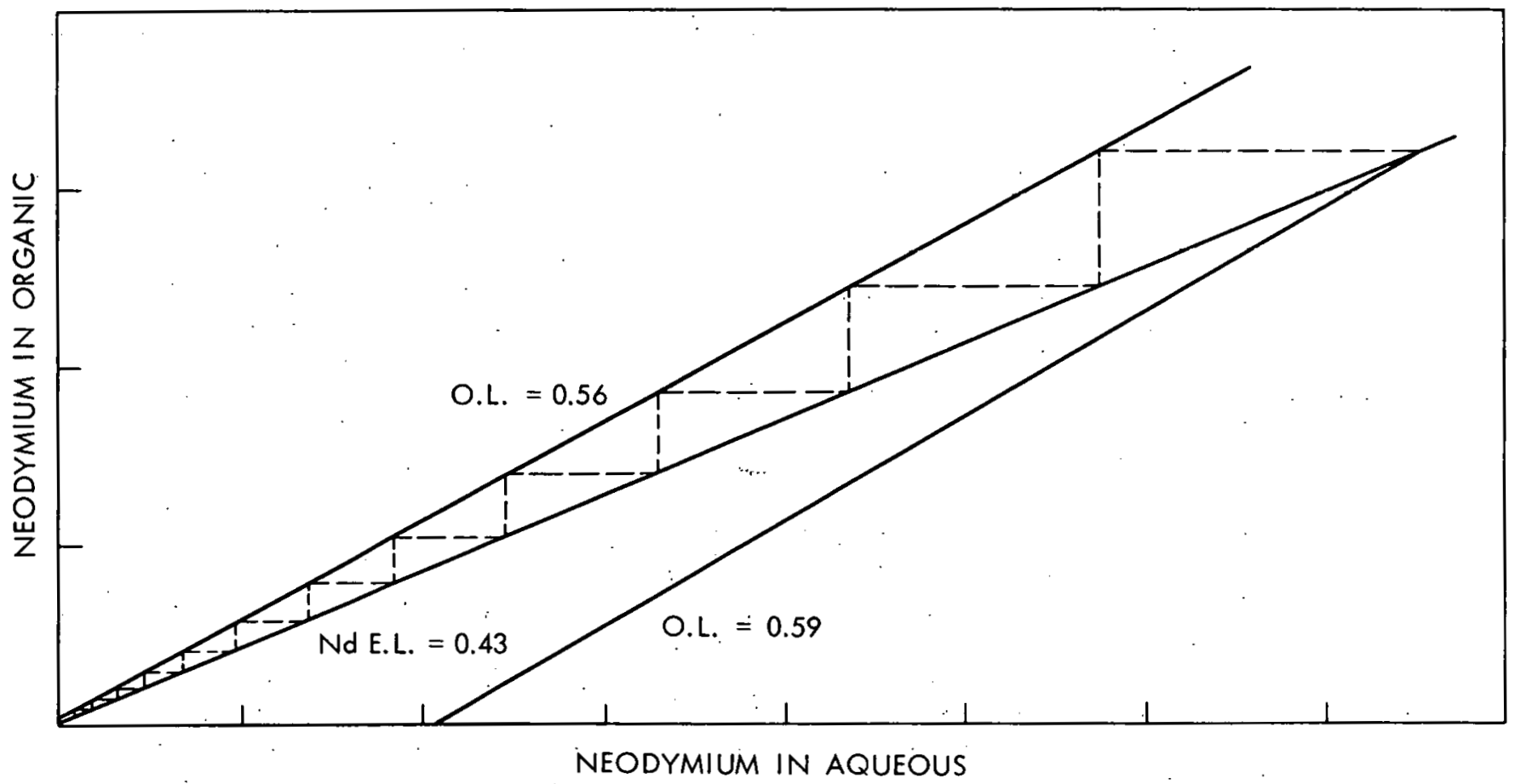

Fig. 11. Determination of feed point for $98 \%$ removal of neodymium from promethium. Arbitrary concentration units. 
The promethium and samarium extraction coefficients are 0.82 and 1.55 . With a feed volume equal to $5 \%$ of the total aqueous flow, the operating lines are 1.07 and 1.13 above and below the feed point. For the calculation, the more extractable element, samarium, is regarded as the element to be recovered. While all the stages behave essentialiy the same in accomplishing separations, the stages from the feed point to the aqueous exit are designated as the extraction section, and those between the feed point and the organic exit as the scrubbing section. Given and derived:

$$
\begin{aligned}
& \mathrm{D}_{\mathrm{Sm}}=\mathrm{E}_{\mathrm{a}}^{\mathrm{O}} \text { for } \mathrm{Sm}=1.55 \\
& \mathrm{D}_{\mathrm{Pm}}=\mathrm{E}_{\mathrm{a}}^{\mathrm{O}} \text { for } \mathrm{Pm}=0.82 \\
& \text { Aqueous flow, } \mathrm{s}=1.9 \text { liters } / \mathrm{hr}
\end{aligned}
$$

Feed flow, $\dot{F}=0.1$ liter $/ \mathrm{hr}$, containing $4.0 \mathrm{~g}$ RE's

Organic flow, $\mathrm{E}=1.77$ liters $/ \mathrm{hr}$

Aqueous feed concentration:

$$
\begin{aligned}
& \text { Samarium, } \quad x_{\mathrm{Sm}}^{\mathrm{F}}=40 \times 0.615=24.6 \\
& \text { Promethium, } \mathrm{x}_{\mathrm{Pm}}^{\mathrm{F}}=40 \times 0.34=13.6
\end{aligned}
$$

Solvent feed concentration:

$$
\begin{array}{ll}
\text { Samarium, } & y_{\mathrm{Sm}, \mathrm{O}}^{E}=0 \\
\text { Promethium, } & \mathrm{y}_{\mathrm{Pm}, \mathrm{O}}^{\mathrm{E}}=0
\end{array}
$$

Samarium recovery, $\rho=\mathrm{Ey}_{\mathrm{Sm}, 1}^{\mathrm{S}} / \mathrm{Fx}_{\mathrm{Sm}}^{\mathrm{F}}=0.995$

Promethium decontamination factor, $f=\frac{y_{S m, 1}^{S} / y_{P m, 1}^{S}}{x_{S m}^{F} / x_{P m}^{F}}=19$

Flow ratios, $\mathrm{S} / \mathrm{E}=1.07$

$$
\begin{aligned}
& E /(F+S)=0.885 \\
& F / E=0.056
\end{aligned}
$$

Number of stages: Extracting, $N$

$$
\text { Scrubbing, } M
$$

Concentrations in organic extract:

$$
\begin{aligned}
& \text { Samarium: } y_{S m, 1}^{S}=\frac{\rho F x_{S m}^{F}}{E}=0.995 \times 0.056 \times 24.6=1.38 \\
& \text { Promethium: } y_{\mathrm{Pm}, 1}^{S}=\frac{y_{S m, 1}^{S} / f}{x_{S m}^{F} / x_{P m}^{F}}=\frac{1.38 / 19}{24.6 / 13.6}=0.40
\end{aligned}
$$

Concentrations in aqueous residue (by material balance): 
Samarium: $\mathbf{x}_{\mathrm{Sm}, 1}^{\mathrm{E}}=\frac{(1-\rho) \mathrm{Fx}}{\mathrm{S}+\mathrm{Fr}}=\frac{0.005 \times 0.1 \times 24.6}{2.0}=0.00615$

Promethium: $x_{\mathrm{Tm}, 1}^{\mathrm{E}}=\frac{\mathrm{Fx} \mathrm{x}_{\mathrm{P}}^{\mathrm{F}}-\mathrm{Ey}_{\mathrm{Pm}, 1}^{\mathrm{S}}}{\mathrm{S}+\mathrm{F}}=\frac{0.1 \times 13.6-1.77 \times 0.40}{2.0}=0.65$

Extraction Factors:

Samarium:

Extracting: $\frac{\mathrm{D}_{\mathrm{Sm}}{ }^{\mathrm{E}}}{\mathrm{S}+\mathrm{F}}=\frac{1.55 \times 1.77}{2.0}=1.38$

Scrubbing: $\frac{\mathrm{D}_{\mathrm{Sm}} \mathrm{E}}{\mathrm{S}}=\frac{1.55 \times 1.77}{1.9}=1.45$

Promethium:

Extracting: $\frac{\mathrm{D}_{\mathrm{Pm}} \mathrm{E}}{\mathrm{S}+\mathrm{F}}=\frac{0.82 \times 1.77}{2.0}=0.73$

Scrubbing: $\frac{D_{\mathrm{Pm}} \mathrm{E}}{\mathrm{S}}=\frac{0.82 \times 1.77}{1.9}=0.77$

Solving for samarium in the equation,

$$
\begin{aligned}
& \frac{(\mathrm{S} / \mathrm{ED})^{\mathrm{M}+1}-1}{\mathrm{~S} / \mathrm{ED}-1} \mathrm{y}_{1}^{\mathrm{S}}=\frac{[\mathrm{DE} /(\mathrm{S}+\mathrm{F})]^{\mathrm{N}}-1}{[\mathrm{DE} /(\mathrm{S}+\mathrm{F})]-1}\left(\mathrm{Dx}_{1}^{\mathrm{E}}-\mathrm{y}_{\mathrm{O}}^{\mathrm{E}}\right)+\mathrm{y}_{\mathrm{O}}^{\mathrm{E}} \\
& \frac{(0.69)^{\mathrm{M}+1}}{0.69-1} \times 1.38=\frac{(1.38)^{\mathrm{N}}-1}{1.38-1} \times 1.55 \times 0.00615 \\
& -4.45(0.69)^{\mathrm{M}+1}+4.45=0.0263(1.38)^{\mathrm{N}}-0.0263
\end{aligned}
$$

Neglecting $(0.69)^{\mathrm{M}+1}$, a small value,

$$
\begin{aligned}
(1.38)^{N} & =170 \\
N & =\frac{\ln 170}{\ln 1.38}=15.9 \text { stages }
\end{aligned}
$$

Solving for promethium,

$$
\frac{(1.30)^{\mathrm{M}+1}-1}{1.30-1} \times 0.04=\frac{(0.73)^{\mathrm{N}}-1}{0.73-1} \times 0.82 \times 0.65
$$




$$
0.133(1.30)^{\mathrm{M}+1}-0.133=-1.97(0.73)^{\mathrm{N}}+1.97
$$

Neglecting $(0.73)^{\mathrm{N}}$,

$$
\begin{aligned}
& (1.30)^{M+1}=15.8 \\
& M+1=\frac{\ln 15.8}{\ln 1.30}=10.5 \\
& M=9.5
\end{aligned}
$$

The calculation indicates that 16 extracting stages and 10 scrubbing stages are required. The calculated separation factor for 26 stages is $1.9^{26 / 2}=4200$. The calculated factor from yield and decontamination factors is $19 \times 200=$ 3800. This is a close check. In a separations cascade with 34 stages there are several stages left for obtaining a higher yield of promethium and/or a higher degree of separation from samarium.

The promethium content of a mixture of cerium-free fission product rare earths will be not more than about $6 \%$, decreasing on aging with a 2.5-year half-life. Any extraction process for its purification consists of two cycles, the first of which reduces the bulk by a factor of about 10 . However, the volume of the organic stream carrying the promethium may approach 50 times the feed volume, or 500 times the feed volume of a second cycle with the same feed concentration. Reduction of volume for feed to the second cycle is accomplished mostly by evaporation, but the necessary capacity of the evaporator is determined by the volume reduction obtainable in stripping the promethium from the first-cycle organic stream. Successful stripping was obtained with a volume reduction of 4 , but the approach to $10 . \mathrm{N} \mathrm{HNO}_{3}$ in the final stage of the stripping section (Fig. 8) indicates the advisability of limiting the organic/aqueous flow ratio to 3 in the stripping section of a production flowsheet. This would maintain the acidity in all stripping stages in the most favorable range. Stripping solutions of at least $2 \mathrm{~N} \mathrm{HNO}_{3}$ are preferred to water because of their higher deñsity and higher stripping coefficients. 


\section{0 REFERENCES}

1. D. F. Peppard, J. P. Faris, P. R. Gray, and G.W. Mason, J. Phys. Chem., 57: 294 (1953); D. F. Peppard, W. J 。 Driscoll, $R_{0}$. J. Sironen, and $S$. McCarty, J. Inorg . Chem。, 4: 326 (1957).

2. D. Scargill, K. Alcock, J. M. Fletcher, E. Hesfórd, and H.A.C. McKay, J. Inorg。 Nucl。Chem ., 4: 304 (1957); E. Hesford, E. E. Jackson, and H.A.C. McKay, J. Inorg. Nucl. Chem., 9: 279 (1959)。

3. J. Bochinski, M. Smutz, and F. H. Spedding, ISC-348 (1953); R: A. Foos and H. A. Wilhelm, ISC-695 (1954); J. Bochinski, M. Smutz, and F. H. Spedding, Ind. Eng. Chem , 50: 157 (1958); L. L. Knapp, M. Smutz, and F. H. Spedding, ISC-766 (1956).

4. B. Weaver, F. A. Kappelmann, and A. C.Topp, J.Am.Chem . Soc., 75: 3943 (1953); ibid., ORNL-1408 (1952); A.C. Topp, ORNL-1409. (1952); A. C. Topp and B.Weaver? ORNL-1811 (1.955); B. Weaver, chap. 10, "Electromagnetically Enriched Isotopes and Mass Spectrometry,"M.L。 Smith, editor, Butterworth's Scientific Publications, London, 1956 .

5. N. E. Brezhneva, V. I. Levin, G. V。Korpusov, N. M. Manko, and E. K. Boguchova, Proc. 2nd Internat1. Conf. on Peaceful Uses of Atomic Energy, Geneva, 1958, P/2295, Vol. 18, p. 219, U. N., New York.

6. B. V. Coplan, J.. K. Davidson, and E. L. Zebrowski, Chem. Eng. Progr., 50: 408 (1954); J.A. Holmes and A. C. Schafer, Chem. Eng. Progr., 52: 201 (1956).

7. M. Benedict and $\mathbb{T}$. H. Pigford, p. 225, "Nuclear Chemical Engineering," McGraw-Hil1, New York, 1957. 


\section{INTERNAL DISTRIBUTION}

1. C. E. Center

2. Biology. Library

3. Health Physics Library

4-5. Central Research Library

6. Reactór Experimental Engineering Library

7-26. Laboratory Records Department

27. Laboratory Records, ORNL R.C.

28. A. M. Weinberg

29. L. B. Emlet $(\mathrm{K}-25)$

30. J. P. Murray $(Y-12)$

31. J. A. Swartout

32. E. H. Taylor

33. E. D. Shipley

34-35. F. L. Cưller

36. M. L. Nelson

37. W. H. Jordan

38. J. B. Adams

39. J. H. Frye, Jr.

40. S. C. Lind

41. G. I. Cathers

42. A. Hollaender

43. F. F. Blankenship

44. M. T. Kelley

45. C. F. Cóleman

46. R. S. Livingston

47. C. P. Keim

48. D. J. Crouse

49. C. E. Winters

50. A. D. Ryon

51. J. H. Gillette

52. W. K. Eister

53. F. R. Bruce

54. D. E. Ferguson

55. R。 B. Lindauer

56. H. E. Goeller

57. R. A. Charpic

58. P. S B Baker

59. M. 'J. Skinner

60. R. E. Blanco
61. G. E. Boyd

62. W. E. Unger

63. A. T. Gresky

64. A. E. Cameron

65. J. R. McNa11y

66. J. W. U1lmann

67. K. B. Brown

68. J. A. Norris

69. B. Weaver

70. J. C. Bresee

71. C. A. B lake

72. J. P. Eubanks

73. K. A. Allen

74. F. M. Scheitlin

75. W. C. Davis

76. R. E: McHenry

77. D. E. Horner

78. J. S. Drury

79. J. C. White

80. J. T. Long

81. R. E. Leuze

82. J. T. Roberts

83. R. H. Rainey

84. F. A. Kappelmann

85. E. M. Shank

86. W. H. Lewis

87. E. Lamb

88. J. H. Goode

89. A. H. Kibbey

90. W. R. Grimes

91. P. M. Reyling

92. R. G. Wymer

93. D. Phillips

94. M. Benedict (consultant)

95. D. L. Katz (consultant)

96. C. E. Larson (consultant)

97. J. H. Rushton (consultant)

98. I. Perlman (consultant)

99. H. Worthington (consultant)

100. ORNL - Y-12 Technical Library, Document Reference Section

\section{EXTERNAL DISTRIBUTION}

101. Division of Research and Development, AEC, ORO

102-658. Given distribution as shown in TID-4500 (15th ed.) under ChemistryGeneral category ( 75 copies - OTS) 